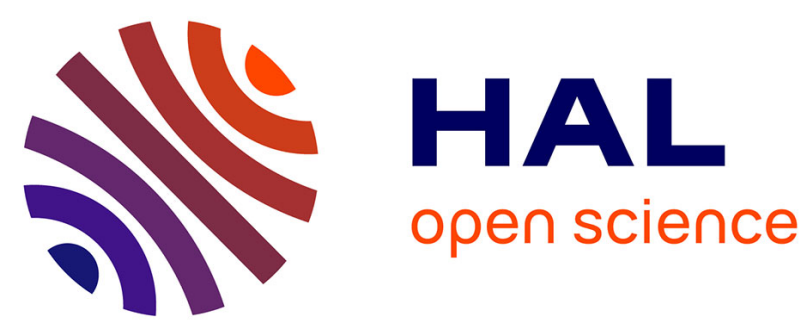

\title{
Firing tests of hybrid engine with varying oxidizer nature and operating conditions
}

\author{
Nicolas Gascoin, Alexandre Mangeot, Camille Marin, Philippe Gillard, \\ Dominique Piton, Stéphane Rouvreau, Jacques Prevost
}

\section{To cite this version:}

Nicolas Gascoin, Alexandre Mangeot, Camille Marin, Philippe Gillard, Dominique Piton, et al.. Firing tests of hybrid engine with varying oxidizer nature and operating conditions. Proceedings of the Institution of Mechanical Engineers, Part G: Journal of Aerospace Engineering, 2013, 10.2514/6.20134047 . hal-01253266

\section{HAL Id: hal-01253266 https://hal.science/hal-01253266}

Submitted on 9 Jan 2016

HAL is a multi-disciplinary open access archive for the deposit and dissemination of scientific research documents, whether they are published or not. The documents may come from teaching and research institutions in France or abroad, or from public or private research centers.
L'archive ouverte pluridisciplinaire HAL, est destinée au dépôt et à la diffusion de documents scientifiques de niveau recherche, publiés ou non, émanant des établissements d'enseignement et de recherche français ou étrangers, des laboratoires publics ou privés. 


\title{
Firing tests of hybrid engine with varying oxidizer nature
}

\section{and operating conditions}

\author{
Nicolas Gascoin ${ }^{1 \mathrm{a}}$, Alexandre Mangeot ${ }^{\mathrm{a}, \mathrm{c}}$, Camille Marin $^{\mathrm{b}}$, Philippe Gillard ${ }^{\mathrm{a}}$, Stéphane Rouvreau ${ }^{\mathrm{b}}$, Jacques Prevost ${ }^{\mathrm{b}}$ \\ and Dominique Piton ${ }^{\mathrm{b}}$ \\ ${ }^{a}$ University of Orléans, France \\ ${ }^{b}$ Roxel France, France \\ ${ }^{c}$ Centre National d'Etudes Spatiales, France
}

\begin{abstract}
Hybrid combustors are of increasing interest for space and civilian propulsion. A test facility has been settled to investigate the high density polyethylene combustion (propellant of $0.15 \mathrm{~m}$ long). A parametric study has been achieved on the oxidiser nature (gaseous oxygen diluted in nitrogen, from 31.4 vol.\% to 69.2 vol.\% of $\mathrm{O}_{2}$ ), on the oxidiser flow rate (from 28.6 g.s $\mathrm{s}^{-1}$ to 53.1 g.s $\mathrm{s}^{-1}$ ), on the combustor pressure (from 11.4 bar to 25 bar) and on the nozzle diameter (from $6.4 \mathrm{~mm}$ to $12.9 \mathrm{~mm}$ ). The regression rate has been estimated by weight loss (mean value of $\left.0.207 \mathrm{mg} . \mathrm{s}^{-1}\right)$ and by thermocouples $\left(0.198 \mathrm{mg} . \mathrm{s}^{-1}\right)$. Its values are compared to existing data through the Marxman law; this enlarges the range of validity of this law. The conduction heat flux in the solid reducer is estimated around $6000 \mathrm{~W}$ to $8000 \mathrm{~W}$; which is related to the low regression rate of the solid fuel. The axial thrust has been measured in addition to other parameters (pressures, temperatures, mass flow rates). Solid particles have been gathered at the combustor outlet to conduct additional chemical analyses. These particles were formed at the surface of the reducer and extracted by the oxidizer from the solid surface.
\end{abstract}

\section{Keywords}

Hybrid rocket engine; combustion; high density polyethylene HDPE; regression rate; Marxman law.

\footnotetext{
${ }^{1}$ Corresponding author : Nicolas Gascoin, University of Orléans, 63 avenue de Lattre de Tassigny, 18020 Bourges Cedex France, Email: nicolas.gascoin@univ-orleans.fr
} 


\section{Introduction}

Hybrid rocket engine involves classically a solid fuel (generally Polybutadiene, Polyethylene, or others [1]-[5]) and a pressurised oxidiser (such as gas/liquid oxygen, peroxide hydrogen, nitrous oxide [1],[5]). The simple oxidiser injection through a valve, which can be regulated [6], and the gaseous combustible generation thanks to the combustion heat flux [1] make this propulsion mode to be of increasing interest, specifically for space and civilian applications [7]-[10]. The hybrid rocket engines are safe (due to the separate storage of the fuel and of the oxidiser). They may be extinguished and reignited during the flight and the thrust can be varied over the time [7]. Numerous studies do exist, either numerically [11]-[13] or experimentally [14]-[17]. A number of test facilities enable to consider large size engines with thrust over $250 \mathrm{kN}$ [17]. A high number of test benches dedicated to hybrid rocket technology are available at reduced scale (lab conditions) or large scale (demonstrator). Some specific mock-up provide data on "isolated" phenomena (regression rate, pressure effect, combustion instabilities and related pressure oscillations, oxidizer injection, ignition device, addition of compounds in solid reducer, formation of a liquid fuel layer) [18]-[23].

Among the available fuels, the high density polyethylene (HDPE) has been studied in several papers [24]-[27]. Its regression rate is estimated around $0.4 \mathrm{~mm} . \mathrm{s}^{-1}$ to $0.8 \mathrm{~mm} . \mathrm{s}^{-1}$ with nitrous oxide or oxygen; which is quite low compared to other fuels. The major advantage of HDPE is its cost and its ease to be purchased and used. Liquefying fuels and additives are investigated since they present higher regression speed. The regression rate and the liquid surface interface, in case of liquefying fuel, are often measured by ultrasonic methods but thin thermocouples are also of great interest for simplicity of use, post-processing and cost reason [1]. Visualization is also feasible but the modification of the refractive indices, due to unstable liquid layer, heat transfer and mass transfer, makes it difficult.

Despite the knowledge which has been developed since over 40 years, the industrial and research communities are still looking for a way to enhance the reducer regression rate in order to increase the engine thrust. Indeed, the major drawback of hybrid engines is due to the fact that the combustion heat release is limited and the resulting combustible formation, on the basis of the solid reducer pyrolysis, is quite low. To cope with the regression limitation, the University of Orléans (France), the Roxel company and the French Space Agency (CNES) have settled a collaboration since 2009 through the CHARME project (French acronym for Hybrid Chamber with Reactive Approach by Modelling and Experiments). A Computational Fluid Dynamics (CFD) code is currently under validation. An experimental test bench at reduced scale (less than one meter long) is also proposed in the 
framework of the CHARME project in order to validate the CFD code and to test transient configurations by adjusting the oxidiser flow rate.

The purpose of this paper is to present the test facility and the associated results which were obtained under quasi steady-state firing configurations. In addition to several measures such as the thrust, the pressure, the flow rates and the temperatures in the system, several thermocouples enable to monitor the regression rate of the solid reducer over the time, axially and longitudinally in the engine. These data present a strong interest to determine the relationship between pyrolysis and combustion. Furthermore, the data are analysed in light of the Marxman law [28] and chemical analyses of the fuel and of the combustion residue are proposed.

\section{Materials and methods}

\section{The CHARME test bench}

The oxidiser injection, the torch ignition, the solid reducer, the nozzle and the thrust sensors are shown on Figure 1a. The corresponding schematic (Figure 1b) shows the location of additional measures, such as the temperature and the pressure -upstream and downstream the solid reducer-. It should be noticed that the thrust is mainly given for illustrative purpose since the nozzle appeared not to be adapted to the flow. As a matter of fact, a clear separation of the jet flow is visible during the experiments, which impacts the quantitative use of the thrust measurements.

The stainless steel mock-up is internally coated by in-house thermal protection made of carbon-based composite ceramic. The nozzle is made of carbon to withstand the large heat load. The solid reducer is the High Density Polyethylene (solid grain of $0.15 \mathrm{~m}$ long with single port, external diameter of $0.09 \mathrm{~m}$ and internal one of $4.10^{-2} \mathrm{~m}$ ). HDPE is provided by Politek (PE1000). The gaseous oxidiser is a tuneable mixture of $\mathrm{O}_{2}$ and $\mathrm{N}_{2}$ by varying their respective feed pressure injected through sonic throat. A flow stabilizer is used to obtain established flow when entering the combustion chamber -for later use in CFD code validation-. After filling up the combustion chamber with the oxidiser and after reaching the expected pressure (which varies depending on the tests, as it is detailed in next section), a $\mathrm{H}_{2}+\mathrm{O}_{2}$ torch is used during $0.3 \mathrm{~s}$, which is enough to ensure the ignition of the HDPE.

All the sensors signals are acquired at a frequency of $62.5 \mathrm{~Hz}$. Some temperature sensors are used on the outer mock-up surface for safety reason in order to limit its heating (damage of the inner thermal protection). At three different longitudinal locations in the solid reducer, the temperature is measured in order to monitor the solid 
regression and to estimate the regression rate. Five thermocouples (K-type, stainless steel coated, 1 mm of external diameter) are positioned every $2 \mathrm{~mm}$ to $3 \mathrm{~mm}$ along the reducer radius for each of these three longitudinal positions (Table 1). The solid reducer is weighted before and after the test to check the mass balance.
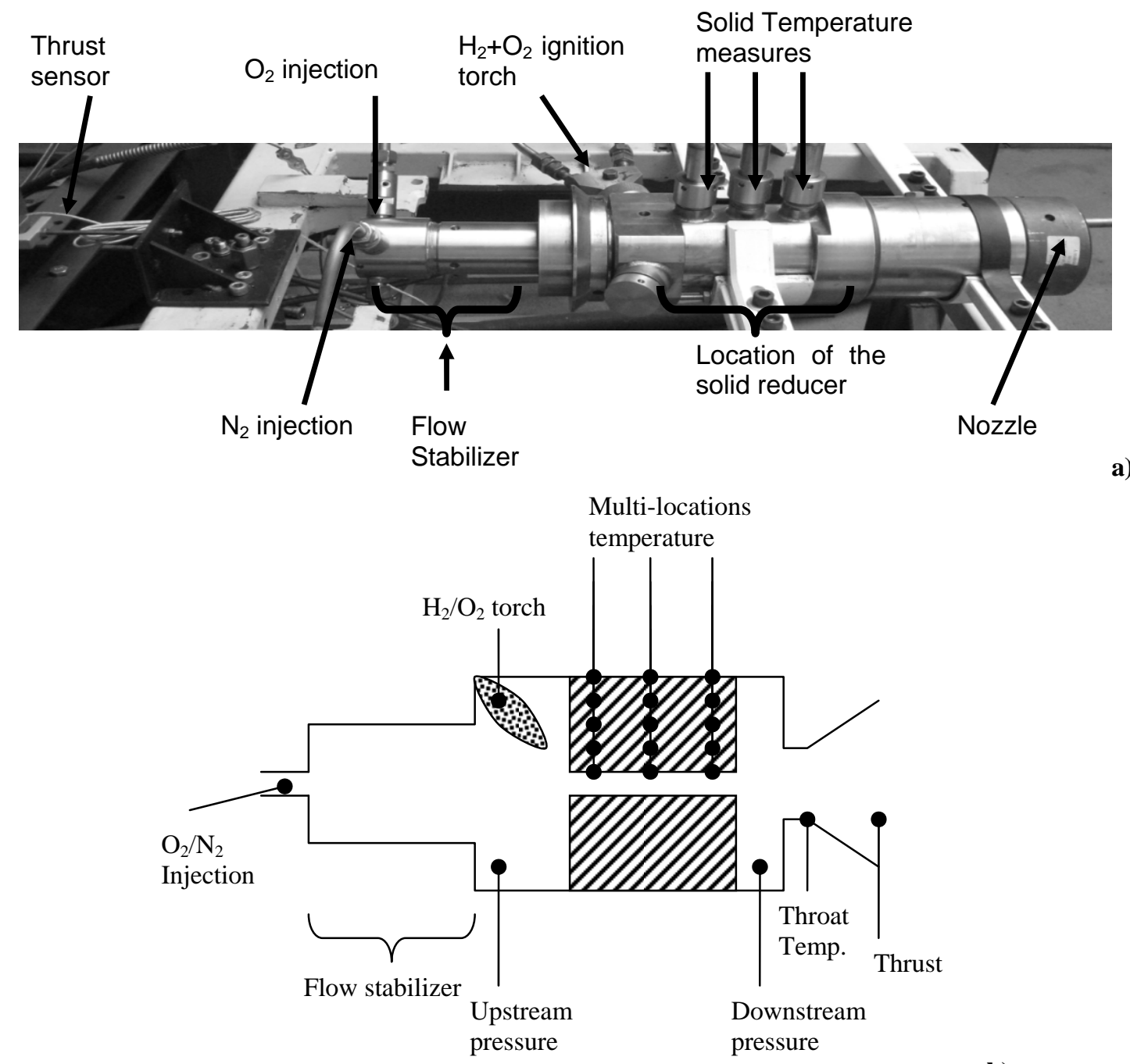

b)

Figure 1. The CHARME Hybrid rocket test bench (a) and the corresponding schematic (b).

Table 1. Radial positions of the thermocouples in the solid reducer ( $r=0 \mathrm{~mm}$ on the central axis).

\begin{tabular}{cccc}
\hline \hline & \multicolumn{2}{c}{ Longitudinal Position from the upstream HDPE border $(\mathrm{m})$} \\
\cline { 2 - 4 } Thermocouple 1 & First position : 23 mm & Second position : 73 mm & Third position : $123 \mathrm{~mm}$ \\
Thermocouple 2 & $21 \mathrm{~mm}$ & $21 \mathrm{~mm}$ & $21 \mathrm{~mm}$ \\
Thermocouple 3 & $24 \mathrm{~mm}$ & $24 \mathrm{~mm}$ & $24 \mathrm{~mm}$ \\
Thermocouple 4 & $27 \mathrm{~mm}$ & $27 \mathrm{~mm}$ & $27 \mathrm{~mm}$ \\
Thermocouple 5 & $30 \mathrm{~mm}$ & $30 \mathrm{~mm}$ & $30 \mathrm{~mm}$ \\
\hline \hline
\end{tabular}


Test conditions

For all the tests, the oxidiser nature (concentration of $\mathrm{O}_{2}$ and of $\mathrm{N}_{2}$ ) and its flow rate change depending on the test number (Table 2). The oxidiser flow rate ranges from $10 \mathrm{~kg} \cdot \mathrm{m}^{-2} \cdot \mathrm{s}^{-1}$ to $60 \mathrm{~kg} \cdot \mathrm{m}^{-2} \cdot \mathrm{s}^{-1}$. The operating pressure is linked to the oxidiser injection and to the nozzle diameter, which slightly varies around $7 \mathrm{~mm}$ to $8 \mathrm{~mm}$ (Table 2). The test duration varies from $80 \mathrm{~s}$ to $102 \mathrm{~s}$, ensuring that most of the solid propellant is consumed. Additional information regarding the five tests is summarized in Table 2. At the end of each test, the combustor is filled with nitrogen to extinguish it and cool it down and to solidify the reducer grain. Each solid fuel is then weighted and geometrically measured to determine the mean regression rate and to observe if this regression is homogeneous spatially.

Table 2. Test conditions of the successive hot experiments.

\begin{tabular}{cccccccc}
\hline \hline $\begin{array}{c}\text { Test } \\
\text { number }\end{array}$ & $\begin{array}{c}\text { Répartition } \\
\text { (vol.\%) } \\
\text { O2 }\end{array}$ & $\begin{array}{c}\text { N2 } \\
\text { content }\end{array}$ & $\begin{array}{c}\text { Oxidiser } \\
\text { flow rate } \\
\left(\mathrm{g} . \mathrm{s}^{-1}\right)\end{array}$ & $\begin{array}{c}\text { Initial grain } \\
\text { diameter } \\
(\mathrm{mm})\end{array}$ & $\begin{array}{c}\text { Mean } \\
\text { combustor } \\
\text { pressure } \\
\text { (bar) }\end{array}$ & $\begin{array}{c}\text { Initial } \\
\text { nozzle } \\
\text { diameter } \\
(\mathrm{mm})\end{array}$ & $\begin{array}{c}\text { Test } \\
\text { duration } \\
(\mathrm{s})\end{array}$ \\
\hline 5866 & 53.6 & 46.4 & 28.6 & 39.7 & 11.4 & 7.3 & 98 \\
5869 & 31.4 & 68.6 & 48.6 & 39.8 & 11.5 & 8.7 & 102 \\
5870 & 69.2 & 30.8 & 47.8 & 39.7 & 12.5 & 8.8 & 83 \\
5871 & 47.6 & 52.4 & 53.1 & 39.6 & 25 & 6.4 & 97 \\
5875 & 52 & 48 & 28.9 & 51 & 11.5 & 7.4 & 80 \\
\hline \hline
\end{tabular}

95

\section{Results and Discussion}

\section{Full post-processing of the test number 5866}

Direct measures of physical parameters. Thanks to the two pressure transducers (upstream and downstream the reducer), the pressure drop (that is to say the inlet pressure minus the outlet one) is monitored (Figure 2a). Its maximum reaches 0.15 bar for an operating pressure around 11 bar. The ignition effect of the torch is observed around $16 \mathrm{~s}$ of experimental time. At this time, the pressure briefly reaches a maximum due to the transient behaviour of the system. Over the entire test length, the pressure remains quite constant up to $75 \mathrm{~s}$ and then decreases of about $20 \%$ from $75 \mathrm{~s}$ to the end of the test (due to the erosion of the nozzle throat). The pressure drop 
variations are difficult to understand (Figure 2a). Because of the regression of the solid fuel, the inner port diameter increases. Thus, the pressure drop should decrease (when considering constant oxidizer mass flow rate). This is what is observed from $20 \mathrm{~s}$ to $45 \mathrm{~s}$ and from $60 \mathrm{~s}$ to $110 \mathrm{~s}$ roughly. Nevertheless, the pressure drop increases from $45 \mathrm{~s}$ to $60 \mathrm{~s}$ (black curve on Figure 2a). Since the solid regression surface increases during the test due to the axisymetric geometry, the quantity of pyrolysed fuel increases. This may compensate the pressure drop. This result is interesting because this could show that the pyrolysed fuel flow rate varies during the engine functioning, as it will be seen later in this section. At some time, the combustible flow rate may increase enough during the test to compensate the pressure drop and at other time it may not be sufficient to compensate this pressure decrease due to geometrical changes of the diameter.

In addition, the knowledge of the mean fuel flow rate during the test enable to compute the mean equivalence ratio, which is about 1.07 (fuel excess compared to stoichiometric value).The fuel quantity produced during the test is about $10 \mathrm{wt} . \%$ to $15 \mathrm{wt} . \%$ the one of the oxidiser, that is to say the mixture ratio is around 6 to 10 . This varies during the test according to the fuel quantity produced as a function of time -since the oxidiser flow rate remains quite constant (Figure 2b)-. The small time-fluctuations, which are observed on the oxidiser flow rate, are due to the inlet pressure regulation system. These oscillations (about $1.2 \%$ of magnitude with a frequency of $0.4 \mathrm{~Hz}$ ) may be visible on the thrust and the pressure signals in the combustor (frequency of $0.4 \mathrm{~Hz}$ and $1 \mathrm{~Hz}$ with $5 \%$ and $3.5 \%$ of magnitude respectively). Considering the mean trend, for stabilised flow rate and pressure, the thrust variation is limited (from $44 \mathrm{~N}$ to $53 \mathrm{~N}$ over the entire test duration from $25 \mathrm{~s}$ to $112 \mathrm{~s}$ ). Moreover, the nozzle throat erosion does not decrease the thrust (Figure 2b). Since the nozzle was initially not specifically designed for the test, an explanation is that the throat ablation drives towards a natural adaptation of the nozzle to the flow and pressures. In addition, the nozzle ablation rate remains quite low (about $27 \mu \mathrm{m} . \mathrm{s}^{-1}$, determined by a throat diameter decrease of $1 \mathrm{~mm}$ over a time of $30 \mathrm{~s}$ from $75 \mathrm{~s}$ to $112 \mathrm{~s}$ ). The nozzle throat starts to be consumed around $75 \mathrm{~s}$ by the hot gases (nozzle throat diameter varies from $7.3 \mathrm{~mm}$ to $8.3 \mathrm{~mm}$ during the experiment). This value is estimated on the basis of the pressure decreases in the combustor (seen on Figure 2a). For comparison purpose, the nozzle ablation appears after only few seconds for solid fuel engines. This difference between hybrid and solid rockets could be explained by a lower hot gas mass flow rate in the present hybrid engine and by a lower gas temperature compared to real solid propellant systems. 
It can be mentioned that the temperature of the nozzle throat is measured by a thermocouple inserted $2 \mathrm{~mm}$ from the surface. Nevertheless, the post-processing of this temperature did not furnish a reliable combustion temperature (about $1200{ }^{\circ} \mathrm{C}$, much lower than the theoretical one of $2680^{\circ} \mathrm{C}$ ) because of the bad thermal contact with the solid material.

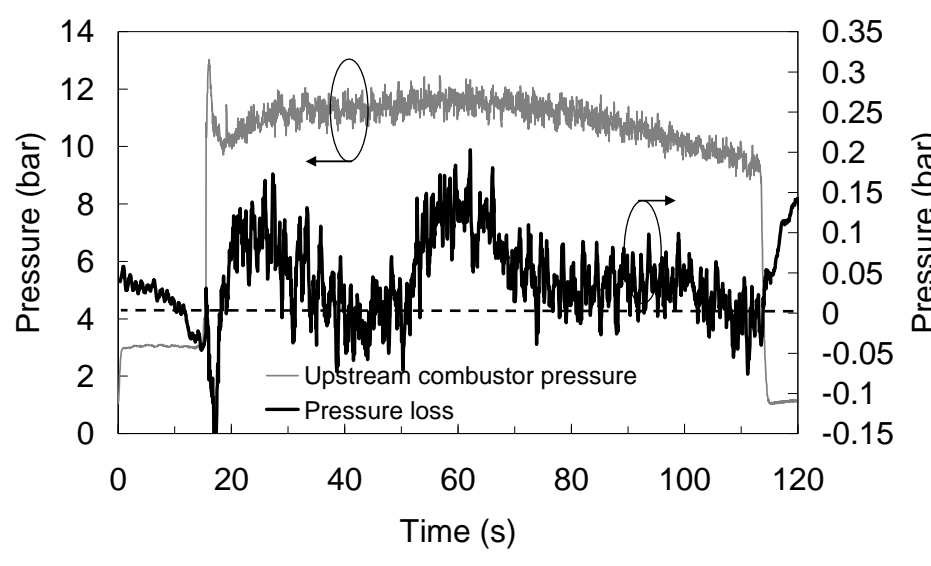

a)

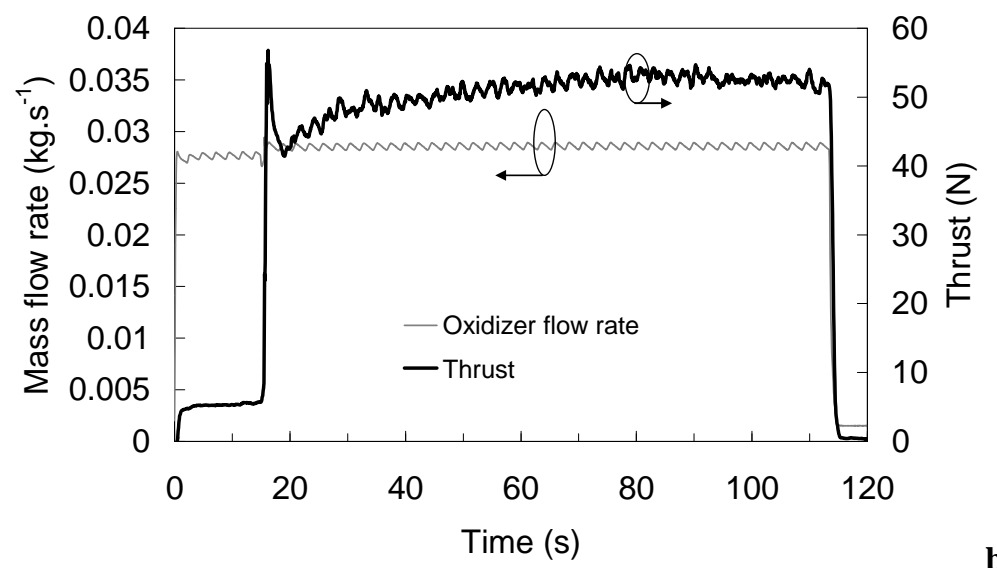

Figure 2. Pressure and pressure drop (between the inlet and the outlet pressure) histories in the hybrid combustor (a) and thrust with oxidizer flow histories (b) for test case number 5866.

Thermal investigations of the solid grain. The temperature measured by each of the fifteen thermocouples along the three longitudinal positions clearly show that most of the solid reducer has been consumed because almost all the thermocouples reach $1200{ }^{\circ} \mathrm{C}$ (Figure 3). At this temperature, it can be assumed that the thermocouple encounters the flame because the signal is lost (they get broken). The maximum peaks can be linked by a line for which the coordinates are marked on each graph. This enables to computeg the regression rate. It can be seen that both thermocouples 4 and 5 (radial position $30 \mathrm{~mm}$ and $33 \mathrm{~mm}$ ) of the first longitudinal position (Figure 3a) reach 1200 
${ }^{\circ} \mathrm{C}$ around $120 \mathrm{~s}$. This behaviour does not match with the line linking the three first peak summits. This is probably caused by a bad insertion in the solid reducer (the position being then erroneous). The last thermocouples (radial position of $33 \mathrm{~mm}$ ) of the longitudinal positions $73 \mathrm{~mm}$ and $123 \mathrm{~mm}$ do not reach $1200{ }^{\circ} \mathrm{C}$ because of the end of the test (Figure 3b and Figure 3c).
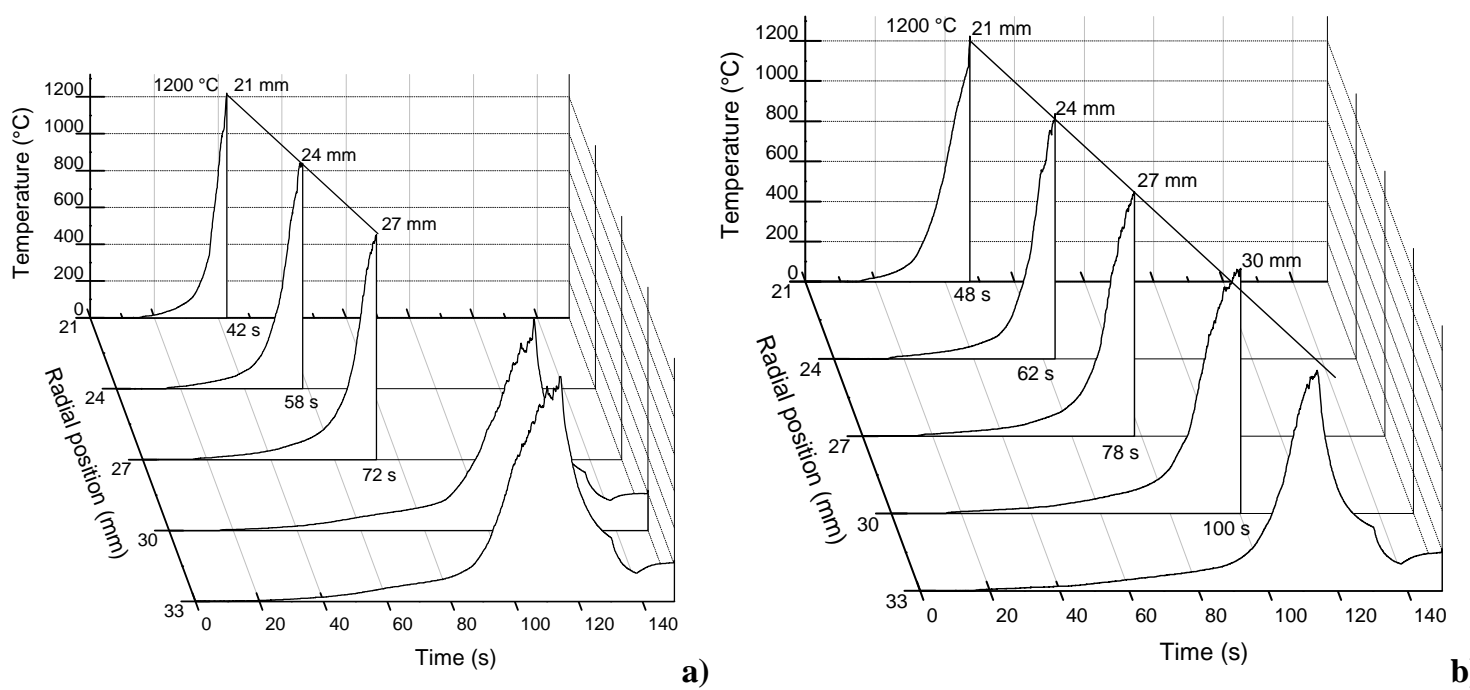

a)

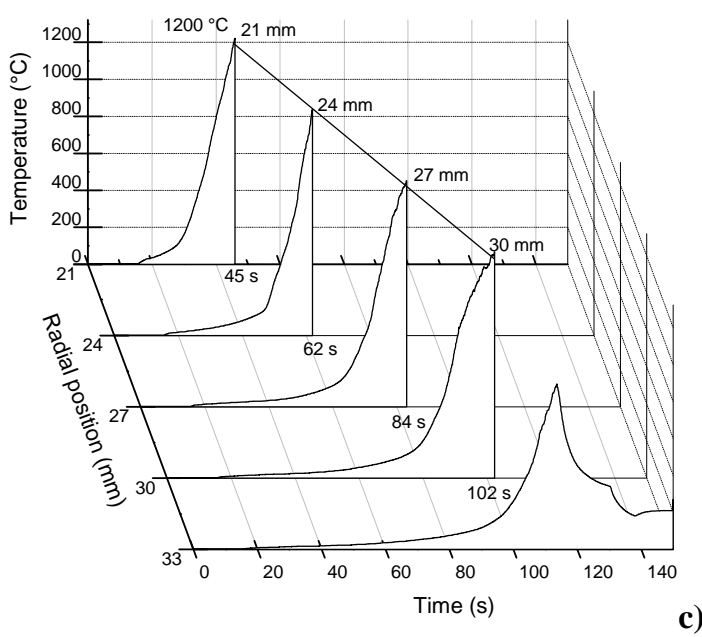

Figure 3. Time histories of the three sets of thermocouples during the test number 5866 from (a) for the upstream position to (c) for the downstream one.

Thanks to these thermal raw data and considering the time to reach the temperature of $1200^{\circ} \mathrm{C}$, the regression rate of the HDPE has been estimated for each thermocouple, knowing their respective positions (Figure 4). The same regression rate estimation has been achieved with $400^{\circ} \mathrm{C}, 600^{\circ} \mathrm{C}, 800^{\circ} \mathrm{C}$ and $1200^{\circ} \mathrm{C}$ criteria without significant changes. The mean regression value of all the data is $0.2 \mathrm{~mm} . \mathrm{s}^{-1}$ with variations from $0.11 \mathrm{~mm} . \mathrm{s}^{-1}$ to 
$0.30 \mathrm{~mm} \cdot \mathrm{s}^{-1}$. Considering the radial position (Figure 4a), the regression seems to show a maximum around $28 \mathrm{~mm}$. The position of this maximum depends in fact of the longitudinal position ( $24 \mathrm{~mm}$ for the first position at $23 \mathrm{~mm}$, $28 \mathrm{~mm}$ at $73 \mathrm{~mm}$ and $31 \mathrm{~mm}$ for the last one at $123 \mathrm{~mm}$ ). The magnitude of this maximum decreases from the upstream part of the combustor to the downstream one. Since the error bars correspond to a relative change of $10 \%$, this trend is significant. The reason of such a maximum could be linked to the time required for the heat transfer to be established and to the time variations of the equivalence ratio (the quantity of combustible changes during the test due to the variation of the regression surface). Accordingly, when plotting the regression rate as a function of the longitudinal position (Figure 4b), the regression decreases along the combustor and this may be attributed again to the equivalence ratio since the oxidiser concentration decreases along the combustor due to the combustion. The data for the radius of $21 \mathrm{~mm}$ are not similar to the others (Figure 4b). This first thermocouple presents a low regression speed (mean value of $0.12 \mathrm{~mm} . \mathrm{s}^{-1}$ ) compared to others (mean value over $0.20 \mathrm{~mm} . \mathrm{s}^{-1}$ ). This is attributed to the time required by the bench to get ignited and to reach a steady-state. Thus, this is a way to estimate the stabilisation time of the system (about 25 s) since the ignition occurs around 18 s (Figure 2b) and this thermocouple is consumed after a time around $42 \mathrm{~s}$ (Figure 3a), $45 \mathrm{~s}$ (Figure 3b) and $48 \mathrm{~s}$ (Figure 3c).
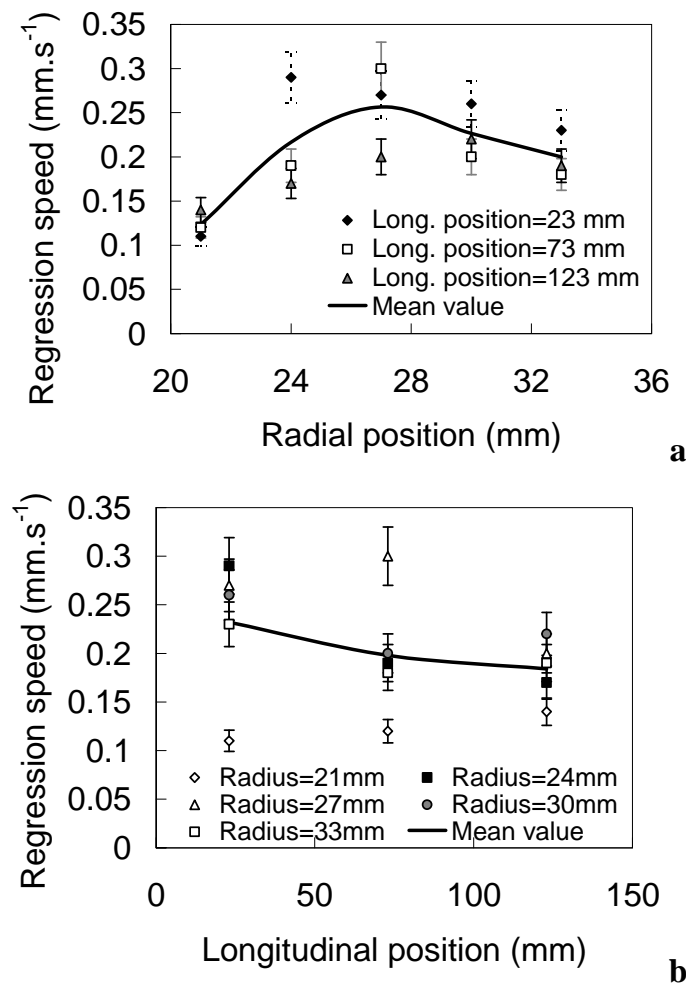
Figure 4. Regression speed given as a function of radial (a) and longitudinal coordinates (b) with data from test number 5866 .

Due to the bad radial position of thermocouples 4 and 5 (radial position $30 \mathrm{~mm}$ and $33 \mathrm{~mm}$ with uncertainty of $1 \mathrm{~mm}$ ) for the first longitudinal position at $23 \mathrm{~mm}$, the uncertainty on the regression rate determination reaches 18.2 \% while it is respectively $9.33 \%$ and $8.99 \%$ for the second and third position.

The thermocouples also enable to observe the thickness of the thermal boundary layer in the solid fuel (Figure 5); that is to say the relationship between the position and the temperature in the solid fuel. This layer is located in the first three millimetres, that is to say close to the solid-gas interface. In addition, by computing the thermal gradient on the basis of these temperature measures, this observation is confirmed and a maximum value of 230 $\mathrm{K} . \mathrm{m}^{-1}$ is obtained. There was a will to determine if a liquid layer appears during the degradation of the HDPE but the thermocouples signals and their derivation can not allow to answer this point. The liquid film should present a thickness (few micrometres) much lower than the distance between two thermocouples (2 mm to 3 mm) and even lower than the size of the thermocouple itself $(1 \mathrm{~mm})$.

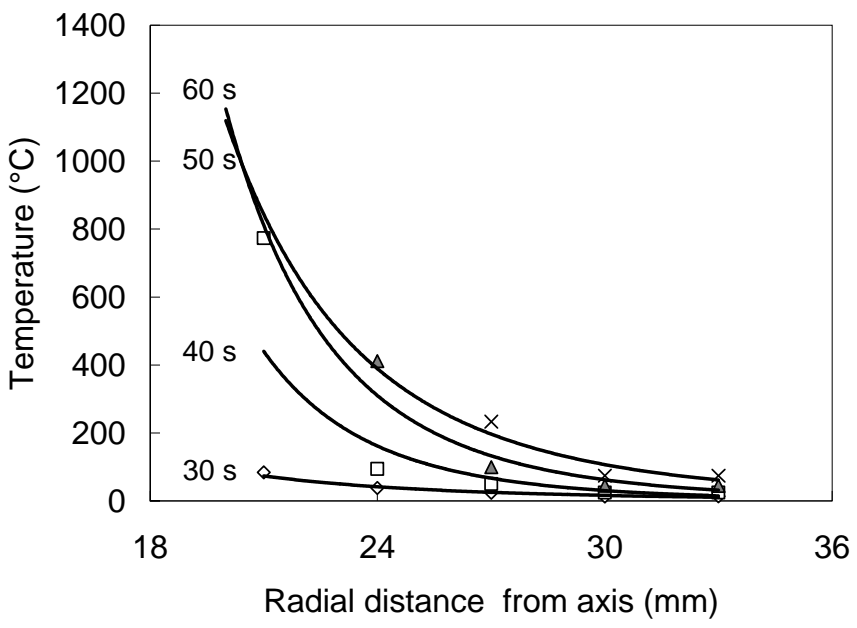

Figure 5. Thermal boundary layer profile at different time step for the test number 5866 .

Chemical investigations of the solid grain. During the firing tests, ejection of incandescent solid particles is clearly visible (Figure 6a). This tends to demonstrate that the combustion of the solid fuel is not complete. After the test, the observations of the solid grain show the presence of solid black particles on the surface of the white HDPE fuel (Figure 6b). To investigate this point, a collector filled with water has been installed downstream the combustor. The gathered black particles have been studied by complementary tools (Scanning Electron Microscope -SEM- with 
Electron Dispersive Scanning -EDS- and Fourier Transform Infrared Spectrometer -FTIR-). The images show aggregates (Figure 7a) with different structures: some with small spherical particles (of the order of few nanometres) (Figure 7b) and some large ones (about $4 \mu \mathrm{m}$ ) (Figure 7c). Their analysis by EDS, whatever the size of the spherical particles, presents a high carbon content (over 95 atom.\%) with a small complementary oxygen content. In addition, the FTIR analysis by Diffuse Reflection reinforces the chemical analysis by showing the molecules bonds (Figure 8a). Hydrogen, carbon and oxygen contents are found. To understand how these oxygenated hydrocarbon particles were formed, a thermal analysis has been achieved with ThermoGravimetric Analysis (Figure 8b). A thermal slope (20 K.min ${ }^{-1}$ ) up to $1000 \mathrm{~K}$ was carried out and the mass loss was monitored under inert (Ar) and oxidative (Air) atmosphere. The pyrolysis under Ar atmosphere shows a mass loss of about 1 wt.\% while the same pyrolysis under Air atmosphere presents a mass loss of $80 \mathrm{wt}$ \% (Figure 8b). This tends to demonstrate that the solid particles are formed at high temperature during the pyrolysis process and are not combustion residue or soot particles because they would not react so much in oxidative atmosphere. This result is important because this shows that a part of the solid reducer is transformed in solid particles which are ejected from the combustor without being burned. This is one of the reasons that explain the low regression rate of the HDPE because this unburned part of fuel does not contribute to the combustion and to the generation of the heat flux for the pyrolysis.

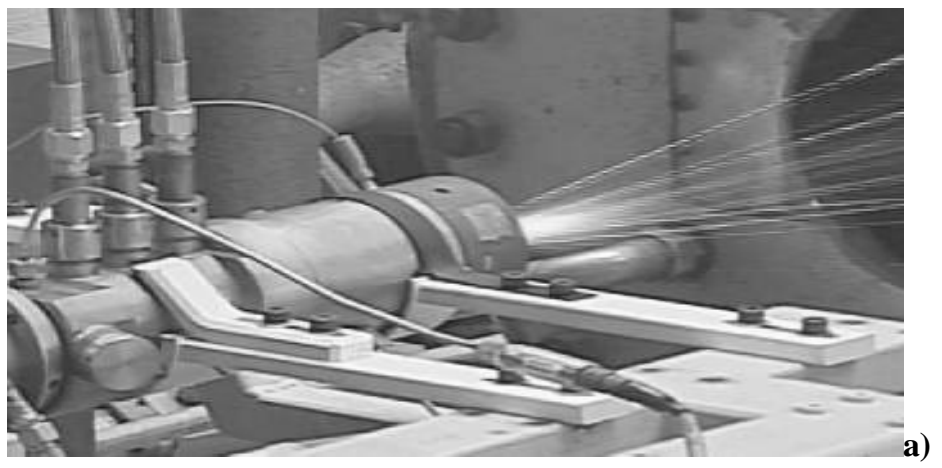


Figure 6. Picture of a firing test with incandescent solid particles ejection (a) extracted from the solid reducer surface (b).
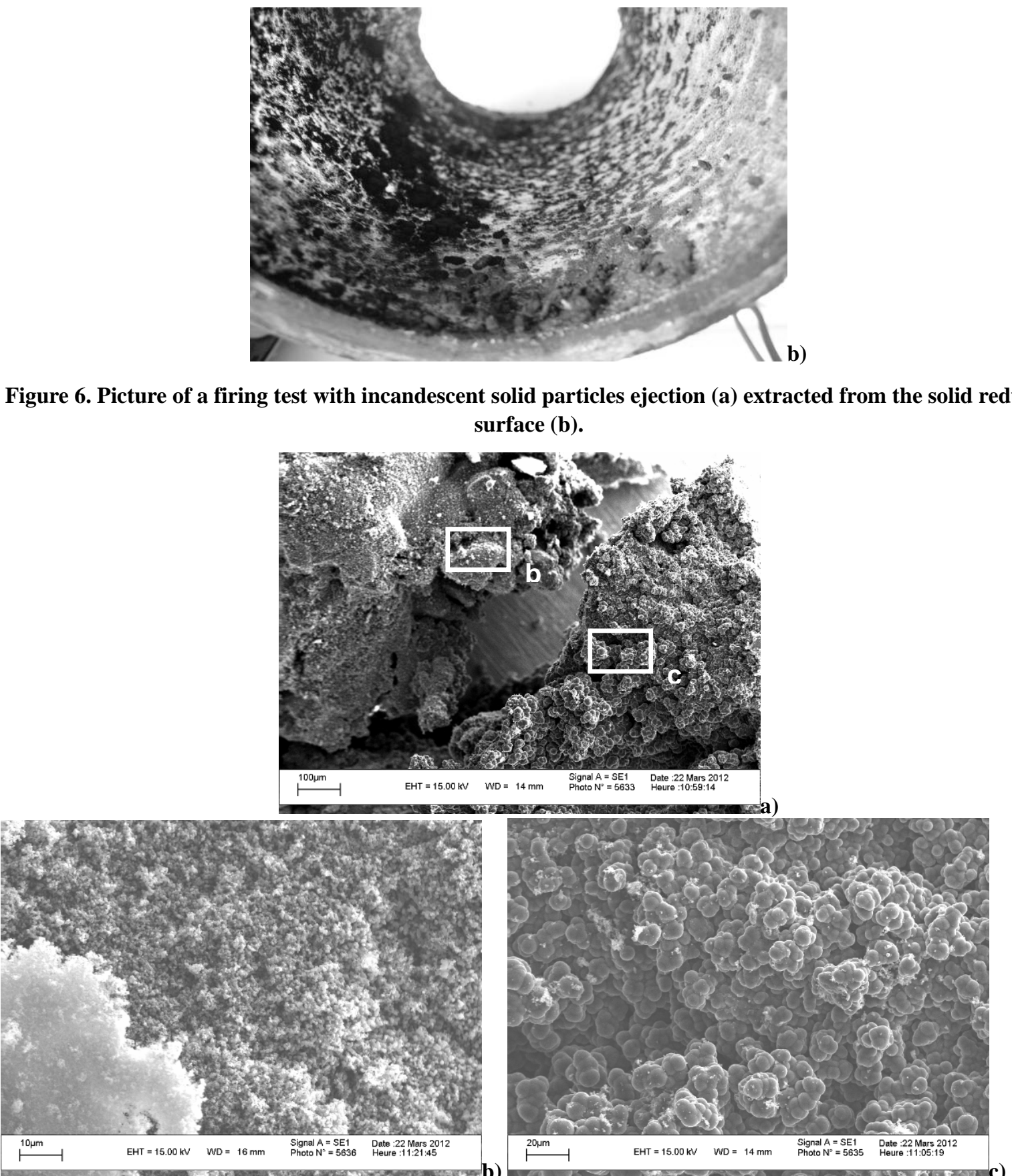

Figure 7. SEM images of the collected solid particles (a-c).

In addition, it can be mentioned that the pressure in the combustor is lower than what could be expected through

0-D calculations with the equilibrium code CEA (considering the following conditions: isentropic case, rocket mode 
fuel, it is possible to determine the amount of fuel which did not participate to the combustion. As a consequence, it

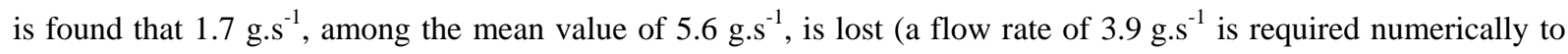
obtain the same pressure as the one measured experimentally). This is about one third of the fuel conversion. This is a major result since this contributes to explain the low HDPE regression rate. This constitutes a way of research for future work if one would require enhancing the HDPE regression.
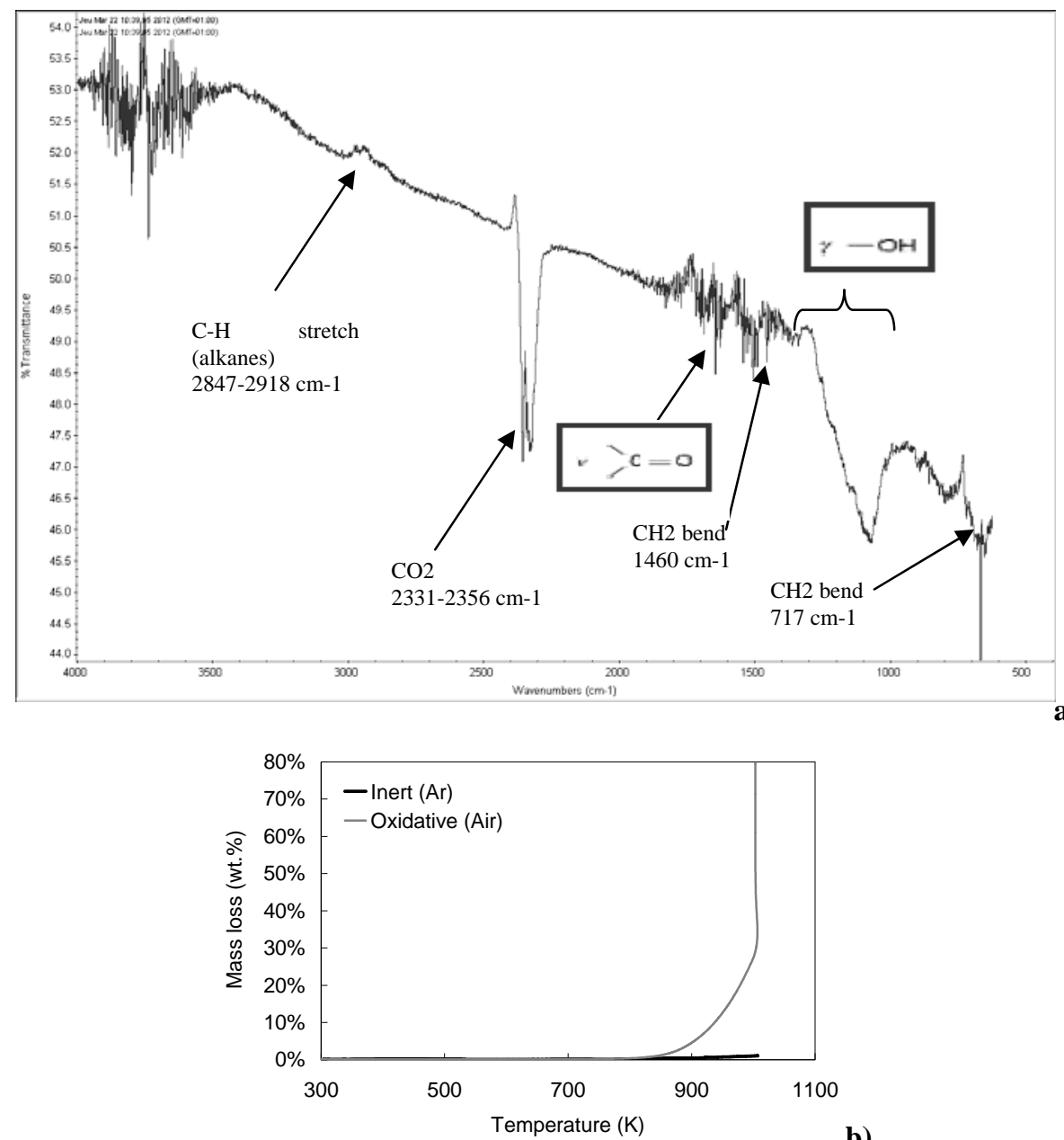

Figure 8. FTIR-DR analysis (a) and Thermogravimetric Analysis of the collected solid particles under inert

Analysis of the entire test campaign and oxidative atmosphere (b).

The data gathered for the five tests have been post-processed (Table 3). The mean fuel flow rate was estimated first through the regression rate measures by thermocouples (in conformity with previous section) and second by weighting the solid reducer before and after the test. A good agreement is obtained (4.2 wt.\% of discrepancy). The 


\begin{tabular}{|c|c|c|c|c|c|c|c|c|}
\hline \multirow{3}{*}{$\begin{array}{c}\text { Test } \\
\text { number }\end{array}$} & \multicolumn{3}{|c|}{ Mean regression rate } & \multirow{3}{*}{$\begin{array}{l}\text { Mean } \\
\text { equivalence } \\
\text { ratio }\end{array}$} & \multirow{3}{*}{$\begin{array}{l}\text { Increase of } \\
\text { the nozzle } \\
\text { diameter } \\
(\mathrm{mm})\end{array}$} & \multirow{3}{*}{$\begin{array}{l}\text { Pressure } \\
\text { yield () }\end{array}$} & \multirow{3}{*}{$\begin{array}{l}\text { Thrust } \\
\text { (N) }\end{array}$} & \multirow{3}{*}{$\begin{array}{l}\text { Conduction } \\
\text { heat flux } \\
\text { (W) }\end{array}$} \\
\hline & \multicolumn{2}{|c|}{$\begin{array}{l}\text { Measured by } \\
\text { thermocouples }\end{array}$} & $\begin{array}{l}\text { Measured } \\
\text { by weight }\end{array}$ & & & & & \\
\hline & $\left(\mathrm{mm} \cdot \mathrm{s}^{-1}\right)$ & $\left(g . s^{-1}\right)$ & $\left(g . s^{-1}\right)$ & & & & & \\
\hline 5866 & 0.2 & 4.8 & 5.02 & 1.06 & 1.0 & 0.92 & 49 & 7081 \\
\hline 5869 & 0.18 & 4.3 & 4.29 & 0.93 & 0.1 & 0.98 & 79 & 6555 \\
\hline 5870 & 0.26 & 6.48 & 6.58 & 0.62 & 4.1 & 0.87 & 86 & 7315 \\
\hline 5871 & 0.18 & 4.5 & 4.91 & 0.53 & 4.5 & 0.95 & 99 & 7847 \\
\hline 5875 & 0.17 & 4.19 & 4.54 & 0.97 & 0.1 & 0.94 & 62 & 5505 \\
\hline
\end{tabular}
thermocouple inserted in the solid fuels (15 per test). The values range from $0.132 \mathrm{~mm} . \mathrm{s}^{-1}$ to $0.239 \mathrm{~mm} . \mathrm{s}^{-1}$ without clear trend. For some tests, the higher value are found at the reducer upstream, for others in the middle or downstream; this changes during the test duration without understandable effect of one or another parameter on 
these variations. Consequently, the analysis presented for the test number 5866 in previous section cannot be easily generalized by taking the pressure or the oxidiser effect into account. While in test 5866, the inner diameter of the reducer along the combustor tended to decrease when reaching the outlet, this trend is not found in other test. This point is complex to explain since it is related to the pressure, to the oxidiser content and surface flow rate, to the nozzle throat and to its ablation. One possible explanation on the basis of the observations during the tests is that at the beginning of the test the regression is higher upstream and this impacts the cross-section area which is higher upstream than downstream. The surface mass flow rate of oxidiser is modified and this increases the regression downstream. Finally, at the end of the test, the combustion channel presents a uniform cross-section. This analysis is supported by some thermocouples analysis and by the visualisation of the solid fuel grains of the tests which were stopped before consuming them entirely.

The maximum instantaneous conduction heat flux has been estimated for each thermocouple and for each test. A linear relationship (mean trend) is found as a function of the time (Figure 9). The values oscillate around this mean line by $\pm 20 \%$. This implies that the operating conditions play a role on this heat transfer but it is limited. The fact that the heat flux is not stable from $0 \mathrm{~s}$ to $60 \mathrm{~s}$ illustrates the fact that due to the solid regression (impacting the equivalence ratio) and to the nozzle damage, a transient evolution of the combustion parameters is found. Regarding the heat flux density for comparison with previous work, the minimum value is measured at $320 \mathrm{~kW} \cdot \mathrm{m}^{-2}$ and the maximum one around $424 \mathrm{~kW} \cdot \mathrm{m}^{-2}$. The previous analytical calculation gave $380 \mathrm{~kW} \cdot \mathrm{m}^{-2}$ [29], which is in good agreement with these measured data. 


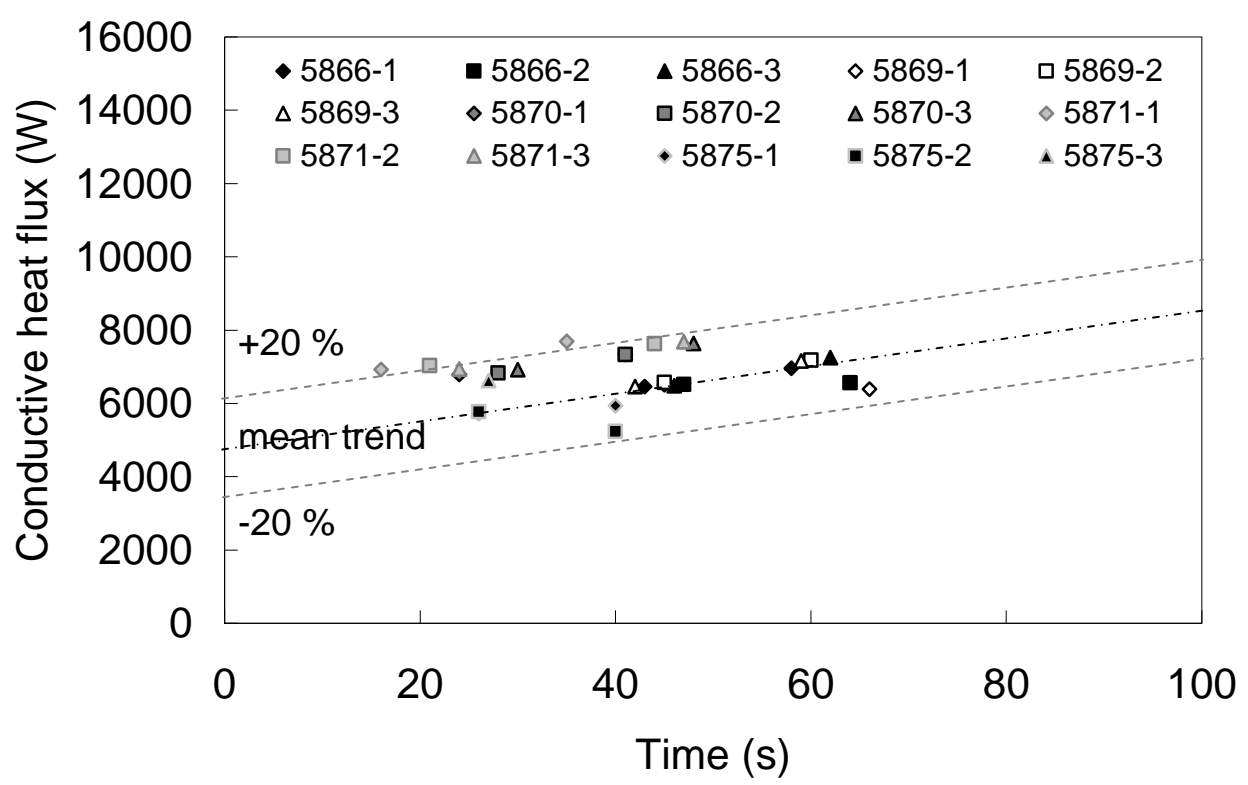

Figure 9. Maximum instantaneous conductive heat flux within the solid reducer as a function of time for all the tests.

Finally, the regression data have been post-processed according to the Marxman law (Eq. 1) [28]. All the data (one for each thermocouple) are given and the mean values (one per test, marked on Figure $\mathbf{1 0}$ with circle and with test number) can be fitted by such an exponential law. The parameters found in this work are $a=0.231$ and $b=0.300$. They can be compared with those from Karabayoglu et al. [24] ( $a=0.143, b=0.468)$, from Zilliac and Karabeyoglu [25] ( $a=0.132, b=0.498)$, from Lohner et al. [26] ( $a=0.234, b=0.356)$, from Soojong et al. [27] ( $a=0.0988, b=0.356)$ and from Carmicino and Russo-Sorge [30] $(a=0.144, b=0.36)$. A good agreement is found, particularly with the work of Lohner et al.. This is particularly interesting because the present data are obtained for an oxidiser flow rate much lower than previous work from the literature. Thus, this enlarges the applicability of the Marxman law.

$$
\dot{r}=a \cdot Q_{o x}^{b}
$$

Where $\dot{r}$ is the regression rate, $Q_{o x}$ the oxidizer flow rate, $a$ and $b$ the solid fuel parameters. 


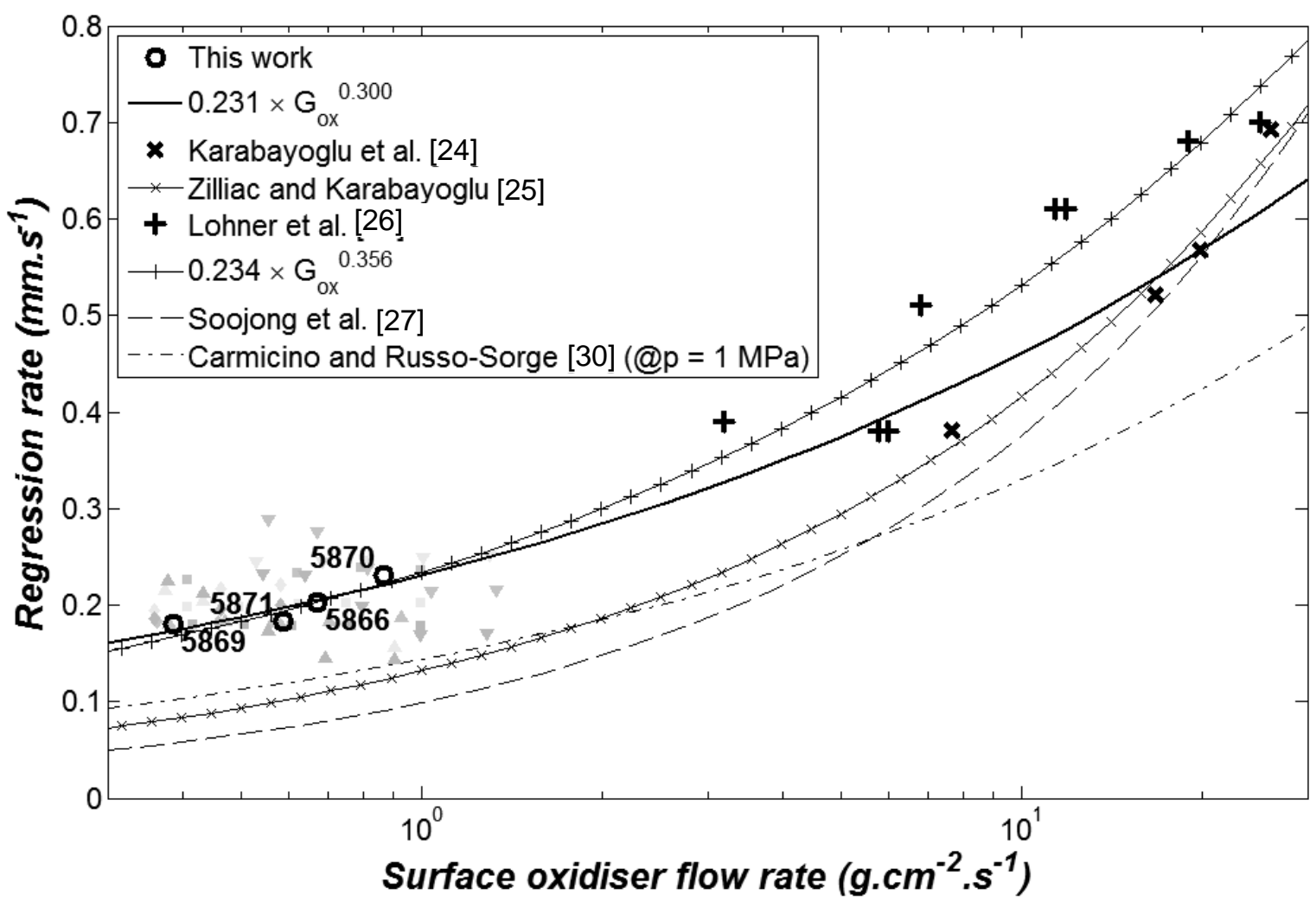

Figure 10. Post-processing of the regression rates according to the Marxman law.

\section{Conclusion}

The hybrid rocket engine presents the advantage of a low cost and safe technology. Scientifically, it is required to understand how the heat release rate in the combustor can impact the solid fuel regression to enhance the generation of combustible fuel and the engine's thrust. As a first step in the present work, the hybrid combustor was presented and the results of the five main tests are detailed. Several parameters were varied to estimate their effects. The regression rate was found to vary from $0.132 \mathrm{~mm} . \mathrm{s}^{-1}$ to $0.239 \mathrm{~mm} . \mathrm{s}^{-1}$ on the basis of thermocouple signals. It was correlated to mass loss measurements with a good agreement (less than $10 \mathrm{wt} \%$ ). The longitudinal and radial regressions were investigated but the effects of the pressure, of the oxidiser flow rate and of its nature were not clearly quantified because of the difficulty to dissociate these coupled parameters. A stabilisation time has been estimated for the engine around 25 s. The maximum conduction heat flux was determined in the solid fuel and linked to the thrust, which is important to understand the heat and mass transfer coupling in the system. This thrust and the regression rate (due to its relationship with the equivalence ratio) are negatively impacted by the fact that 
solid particles are formed during the pyrolysis and that they are ejected by the flow without being burned. Thus, a part of the heat flux used to pyrolyse the fuel is lost through the ejection of these combustible particles. This unburned fuel quantity is about one third the one which is pyrolysed during the solid regression. A nozzle throat ablation has been identified due to the oxygen excess (equivalence ratio often lower than 1). Finally, the data were post-processed according to the Marxman law and its parameters are in good agreement with the literature.

\section{References}

[1] Chiaverini, MJ, Kuo, KK. Fundamentals of Hybrid Rocket Combustion and Propulsion, Progress in Astronautics and Aeronautics, AIAA, Vol. 218, 2007.

[2] Maggi F, Gariani G, Galfetti L, DeLuca LT. Theoretical analysis of hydrides in solid and hybrid rocket propulsion, Int J Hydrogen Energ 2012; 37(2): 1760-1769.

[3] Greatrix DR. Regression rate estimation for standard-flow hybrid rocket engines, Aerosp Sci Technol 2009; 13(7): 358-363.

[4] DeLuca LT, Galfetti L, Maggi F, Colombo G, Merotto M, Boiocchi M, Paravan C, Reina A, Tadini P, Fanton L. Characterization of HTPB-based solid fuel formulations: Performance, mechanical properties, and pollution, Acta Astronaut 2012; 10.1016/j.actaastro.2012.05.002.

[5] Cheung WS, Tilston JR, Testing of a novel propulsion system for micro air vehicles, P I Mech Eng G-J Aer 2001; 215(4): 207-218

[6] Carmicino C and Russo Sorge A. Role of Injection in Hybrid Rockets Regression Rate Behavior, J Propul Power 2005; 21(4)

[7] Davydenko NA, Gollender RG, Gubertov AM, Mironov VV, Volkov NN. Hybrid rocket engines: The benefits and prospects, Aerosp Sci Technol 2007; 11: 55-60.

[8] Stone D, Lindenmoyer A, French G, Musk E, Gump D, Kathuria C, Miller C, Sirangelo M, Pickens T. NASA’s approach to commercial cargo and crew transportation, Acta Astronaut 2008; 63: 192-197.

[9] Karabeyoglu MA, Altman D, Cantwell BJ. Combustion of Liquefying Hybrid Propellants: Part 1, General Theory, J Propul Power 2002; 18(3): 610-620.

[10] Altman D. Rocket Motors, Hybrid, Encyclopedia of Physical Science and Technology (Third Edition), 2004, 303-321 
[11] Gariani G, Maggi F, Galfetti L. Numerical simulation of HTPB combustion in a 2D hybrid slab combustor, Acta Astronaut 2011; 69(5-6): 289-296.

[12] Salva JJ, Tizon JM, Jenaro G, Lopez Agudo C. Numerical analysis of heterogeneous combustion in a ducted rocket, P I Mech Eng G-J Aer 2007; 221(1): 115-127.

[13] Antoniou A and Akyuzlu KM. A Physics Based Comprehensive Mathematical Model to Predict Motor Performance in Hybrid Rocket Propulsion Systems, in: 41st AIAA/ASME/SAE/ASEE Joint Propulsion Conference \& Exhibit 10 - 13 July 2005, Tucson, Arizona, paper nº AIAA 2005-3541

[14] Karabeyoglu MA and Cantwell BJ. Combustion of Liquefying Hybrid Propellants: Part 2, Stability of Liquid Films, J Propul Power 2002; 18(3): 621-630.

[15] Karabeyoglu MA, Zilliac G, Cantwell BJ, DeZilwa S, Castellucci P. Scale-Up Tests of High Regression Rate Paraffin-Based Hybrid Rocket Fuels, J Propul Power 2004; 20(6): 1037-1045.

[16] Cai G, Zeng P, Li X, Tian H, Yu N. Scale effect of fuel regression rate in hybrid rocket motor, Aerosp Sci Technol 2011; 10.1016/j.ast.2011.11.001.

[17] Nagata H, Ito M, Maeda T, Watanabe M, Uematsu T, Totani T, Kudo I. Development of CAMUI hybrid rocket to create a market for small rocket experiments, Acta Astronaut 2006; 59(1-5): 253-258.

[18] Zheng G, Wichman IS, Bénard A. Opposed-Flow Flame Spread Over Polymeric Materials: Influence of Phase Change, Combust Flame 2001; 124: 387-408.

[19] Han CY. Radiative combustion of pyrolyzing fuel in a cylindrical combustor, Fuel 2004; 83: 343-351.

[20] Cantrell RH, Hart RW, McClure FT. Combustion Instability in Solid Propellant Rockets: Linear Acoustic Gains and Losses in Solid Propellant Rocket Motors, AIAA J 1964; 2(6): 1100-1135.

[21] Cantrell RH. Gas-Film Effects in the Linear Pyrolysis of Solids, AIAA J 1963; 1(7): 1544-1560.

[22] Jackson TL and Buckmaster J. Heterogeneous Propellant Combustion, AIAA J 2002; 40(6).

[23] Chiaverini MJ, Serin N, Johnson DK, Lu YC, Kuo KK, Risha GA. Regression Rate Behavior of Hybrid Rocket Solid Fuels, J Propul Power 2000; 16(1).

[24] Karabeyoglu MA, Cantwell BJ, Stevens J. Evaluation of Homologous Series of Normal-Alkanes as Hybrid Rocket Fuels, in: 41st AIAA/ASME/SAE/ASEE Joint Propulsion Conference \& Exhibit; Tucson, AZ; USA; 10-13 July 2005, paper n AIAA-2005-3908 
[25] Zilliac G and Karabeyoglu MA. Hybrid Rocket Fuel Regression Rate Data and Modeling, in: 42nd AIAA/ASME/SAE/ASEE Joint Propulsion Conference \& Exhibit. Sacramento (California), Sacramento, California, July 9-12, 2006, paper n AIAA-2006-4504.

[26] Lohner K, Dyer J, Doran E, Dunn Z, Zilliac G. Fuel Regression Rate Characterization Using a Laboratory Scale Nitrous Oxide Hybrid Propulsion System, in: 42nd Joint Propulsion Conference, Sacramento, California, July 9-12, 2006, paper nAIAA-2006-4671,

[27] Soojong K, Jungpyo L, Heejang M, Honggye S, Jinkon K, Jungtae C. Effect of Paraffin-LDPE Blended Fuel in Hybrid Rocket Motor, in: 46th AIAA/ASME/SAE/ASEE Joint Propulsion Conference \& Exhibit. Nashville, TN, July 25-28, 2010, paper n AIAA-2010-7031.

[28] Marxman G and Gilbert M. Turbulent Boundary Layer Combustion in the Hybrid Rocket, 9th International Symposium on Combustion, Academic Press, 1963, 371-372

[29] Gascoin N, Gillard P, Mangeot A, Navarro-Rodriguez A. Literature survey for a first choice of a fuel-oxidiser couple for hybrid propulsion based on kinetic justifications, J Anal Appl Pyrol 2012; 94: 1-9.

[30] Carmicino C and Russo Sorge A. Performance comparison between two different injector configurations in a hybrid rocket, Aerosp Sci Technol 2007; 11(1): 61-67. 